\title{
An Integrated Hydrological and Water Management Study of the Entire Nile River System - Lake Victoria to Nile Delta
}

\author{
Shahid Habib ${ }^{\mathrm{a}}$, Benjamin Zaitchik ${ }^{\mathrm{b}}$, Clement Alo ${ }^{\mathrm{b}}$, Mutlu Ozdogan $^{\mathrm{c}}$, Martha Anderson ${ }^{\mathrm{d}}$, Fritz Policellia \\ ${ }^{a}$ NASA Goddard Space Flight Center, Greembelt, Maryland, USA \\ bohns Hopkins University, Baltimore, Maryland, USA \\ ${ }^{c}$ University of Wisconsin, Madison, Wisconsin, USA \\ ${ }^{\mathrm{d}}$ United States Dept. of Agriculture, Agriculture Research Services, Beltsville, Maryland, USA
}

Abstract: The Nile basin River system spans 3 million $\mathrm{km}^{2}$ distributed over ten nations. The eight upstream riparian nations, Ethiopia, Eretria, Uganda, Rwanda, Burundi, Congo, Tanzania and Kenya are the source of approximately $86 \%$ of the water inputs to the Nile, while the two downstream riparian countries Sudan and Egypt, presently rely on the river's flow for most of the their needs. Both climate and agriculture contribute to the complicated nature of Nile River management: precipitation in the headwaters regions of Ethiopia and Lake Victoria is variable on a seasonal and inter-annual basis, while demand for irrigation water in the arid downstream region is consistently high. The Nile is, perhaps, one of the most difficult trans-boundary water issue in the world ${ }^{1}$, and this study would be the first initiative to combine NASA satellite observations with the hydrologic models study the overall water balance in a to comprehensive manner. The cornerstone application of NASA's Earth Science Research Results under this project are the NASA Land Data Assimilation System (LDAS) ${ }^{2}$ and the USDA Atmosphere-Land Exchange Inverse (ALEXI) ${ }^{3}$ model. These two complementary research results are methodologically independent methods for using NASA observations to support water resource analysis in data poor regions. Where an LDAS uses multiple sources of satellite data to inform prognostic simulations of hydrological process, ALEXI diagnoses evapotranspiration and water stress on the basis of thermal infrared satellite imagery.

Specifically, this work integrates NASA Land Data Assimilation systems into the water management decision support systems that member countries of the Nile Basin Initiative (NBI) and Regional Center for Mapping of Resources for Development (RCMRD, located in Nairobi, Kenya) use in water resource analysis, agricultural planning, and acute drought response to support sustainable development of Nile Basin water resources. The project is motivated by the recognition that accurate, frequent, and spatially distributed estimates of the water balance are necessary for effective water management. This creates a challenge for watersheds that are large, include data poor regions, and/or span multiple nations. All of these descriptors apply to the Nile River basin, yet successful management of the Nile is critical for development and political stability in the region. For this reason, improved hydrological data to support cooperative water management in the Nile basin is a priority for USAID, the US State Department, the World Bank and other international organizations. In this project, the U.S. 
based research team is working with partners at RCMRD, Nile Basin Initiative (NBI), and their member national-level agencies to develop satellite-based land cover maps, satellite-derived evapotranspiration estimates (using the ALEXI algorithm), and NASA's Land Data Assimilation System (LDAS) customized to match identified information needs. The cornerstone applied sciences product of the project is the development of a customized "Nile LDAS" that will produce optimal estimates of hydrological states and fluxes, as vetted against the in situ observations of NBI and RCMRD member organizations and independent satellite-derived hydrological estimates ${ }^{4}$. Nile LDAS will be applied to improve the reliability of emerging Decision Support Systems in applications that include drought monitoring, reservoir management, and irrigation planning. The end-users such as RCMRD, NBI, Ethiopian and Kenya Meteorological and Famine Early Warning System Network (FEWSNet) will be the eventual benefactors of this work. There will be a capacity building process involving the above end-user organizations and transfer the models and the results for these organizations to execute for future use.

The team has already initiated this study and the early results of first years' work are shown in Figure 1 below. The plan is to complete this work by late 2013 .

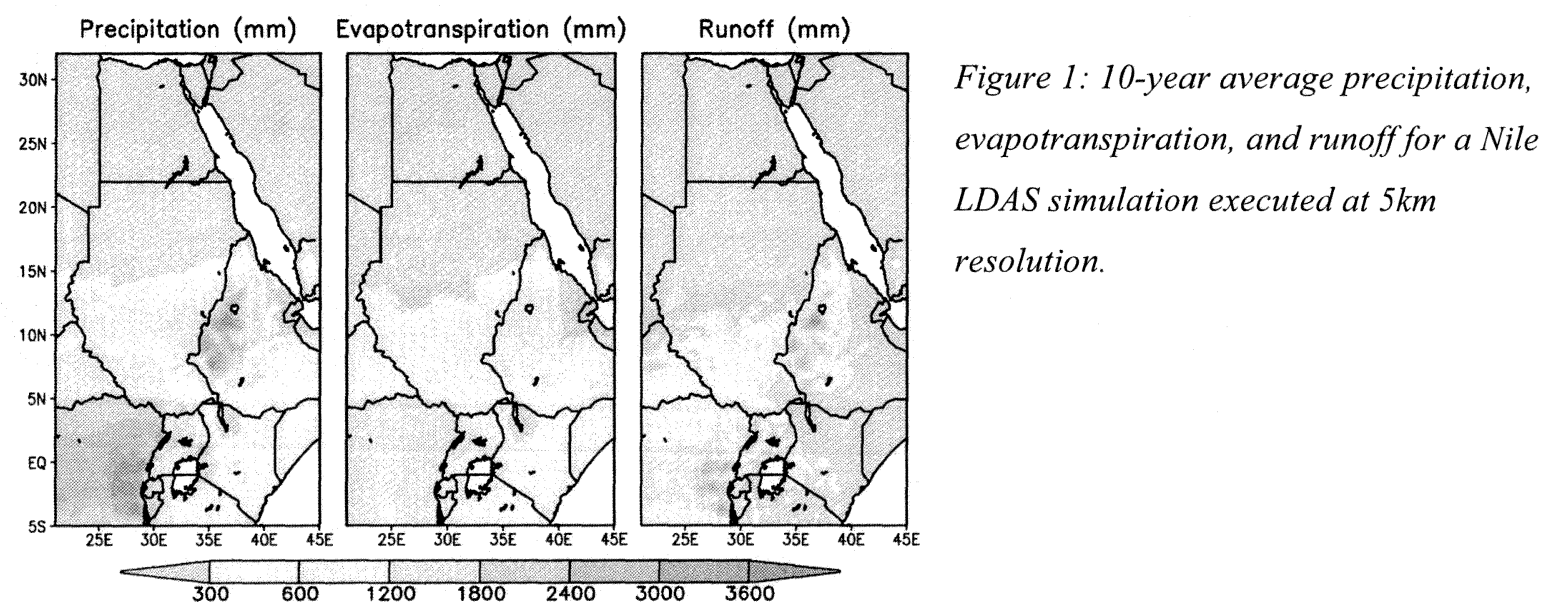

References:

1. Habib, S., "The hydrologic cycle and the sustainability of water resources," Elements of Life, World Meteorological Organization, ISBN 92-63-11021-2, 2007, 62-65.

2. Rodell, M., P. R. Houser, U. Jambor, J. Gottschalck, K. Mitchell, C. J. Meng, K. Arsenault, BCosgrove, J. Radakovich, M. Bosilovich, J. K. Entin, J. P. Walker, D. Lohmann, and D. Toll, March 2004: The global land data assimilation system BAMS, 381-394.

3. Anderson, M.C., W. P. Kustas, J. M. Norman, C. R. Hain, J. R. Mecikalski, L. Schultz, M. P. Gonz'alez Dugo, C. Cammalleri, G. d'Urso, A. Pimstein, and F. Gao, "Mapping daily evapotranspiration at field to global scales using geostationary and polar orbiting satellite imagery," Hydrology. Earth System Sciences Discussions, 1-34, July 2010.

4. Zaitchik, B. F., M. Rodell, and R. H. Reichle, 2008: Assimilation of GRACE terrestrial water storage data into a Land Surface Model: Results for the Mississippi River basin. Journal of Hydrometeorology, 9, 535-548. 